\title{
КЛИПОВОСТЬ МЫШЛЕНИЯ И РЕАЛИЗАЦИЯ ПРИНЦИПА СИТУАТИВНОСТИ В ПРОЦЕССЕ ОБУЧЕНИЯ ПОЛЬСКИХ УЧАЩИХСЯ МЕЖКУЛЬТУРНОМУ ОБЩЕНИЮ НА РУССКОМ ЯЗЗЫКЕ
}

\section{CLIP THINKING AND THE IMPLEMENTATION OF THE SITUATIONALITY PRINCIPLE IN THE PROCESS OF TEACHING INTERCULTURAL COMMUNICATION IN RUSSIAN TO POLISH STUDENTS}

\author{
ОЛЬГА МАКАРОВСКА
}

\begin{abstract}
The article deals with issues of using situational rules in teaching the Russian language to Polish students with regard to their personality traits that have been conditioned by the clip type of thinking. The article also discusses the influence that clip thinking has on students' emotional sphere and its reflection in Russian language acquisition. The article presents certain proposals for including emotive factors in communicative situations and for coordinating situational and communication exercises during Russian language classes.
\end{abstract}

Olga Makarowska, Uniwersytet im. Adama Mickiewicza w Poznaniu, Poznań - Polska.

Общеизвестно, что одним из аспектов обучения русскому языку как иностранному (РКИ) является подготовка учащихся к межкультурному устноречевому общению1, осуществляемому в разных ситуациях.

1 А) Межкультурное общение понимаем как межличностное смысловое взаимодействие участников носителей-пользователей разных культур, осуществляемое в диаде/триаде (в последнем случае два собеседника являются репрезентантами одной культуры). Оно, как известно, может иметь различные характер (прямой/ опосредованный, (не)институциональный, конфликтный и др.), продолжительность, степень официальности; может преследовать разные цели (коммуникативные, деятельностные, отношенческие), осуществляться в (не)привычных условиях и в разное время, на (не)родном языке или на языке-посреднике. Поэтому здесь имеем в виду межкультурное общение, протекающее в условиях повседневности и предполагающее институциональное общение и коммуникацию свободного характера, непосредственный и опосредованный (по телефону) контакт, возможность наличия (пред)конфликтных обстоятельств, в привычной и непривычной (в стране изучаемого языка) обстановке, относительную кратковременность общения, гендерную неограниченность, разнообразные цели и задачи. Одним словом, все то, с чем сталкиваемся в повседневной жизни. Б) Институциональное общение - „профессиональное ролевое и по преимуществу предметно-целевое общение" 
Несмотря на достаточно высокую теоретическую и практическую разработанность вопросов, касающихся ситуативности и (межкультурного) общения, и обучения РКИ, а также на богатый опыт в применении технологии моделирования разнообразных ситуаций и использования ситуативного метода² ${ }^{2}$ проблема ситуативности остается актуальной.

Обоснованность обращения к этой проблематике определяют изменения личностных характеристик субъекта обучения (польских учащихся филологических вузов), степень выраженности которых возрастает год от года, впрочем, как и степень воздействия на процесс обучения вообще и на реализацию принципа ситуативности в частности.

Эти изменения обусловлены формированием у обучающихся клипового мышления, которое влияет не только на их когнитивную, но и эмотивную ${ }^{3}$, ценностно-отношенческую, установочную и другие сферы, что находит отражение в поведении, поступках, действиях, в т.ч. и в процессе обучения. Подробнее остановимся на проявлениях клиповости мышления на эмотивном уровне ${ }^{4}$, в той или иной мере проступающих у польских учащихся, изучающих РКИ.

(М.В. К о л т у н о в а, Конвенциинализация директивных иллкутивных актов в письменном и устном институцииональном общении, [в:] Язык. Сознание. Коммуникация, ред. В.В. Красных, А.И. Изотов, Москва 2004, вып. 28, с. 131-141, [электронный ресурс:] http://www.philol.msu.ru/ slavphil/books/jsk_28.pdf [21.07.2010]). Здесь имеем в виду коммуникацию, проходящую не на линии сотрудник институции - сотрудник той же/другой институции, а на линии сотрудник институции - заинтересованное ıицо (клиент, пациент, студент, покупатель, жалующийся и пр.).

2 А) Вопросы ситуативности обучения РКИ, в т.ч. польских учащихся, активно разрабатываются с середины 60-х годов прошлого столетия (на эту тему см.: M. D z i e k o ń s k i, Metoda sytuacyjna w nauczaniu języka rosyjskiego, Warszawa 1971, c. 8-18). Б) Под ситуативным методом понимаются способы, приемы обучения ситуационного типа, „средства презентации, закрепления или применения учебного материала" (М. D z i e k o ń s k i, указ. соч., с. 8).

${ }^{3}$ А) Клиповое мышление - „разновидность познавательного процесса, направленная на охват постоянно поступающих сведений и быстро (с)меняющихся фактов, образов, вещных реалий действительности и основывающаяся на приеме и переработке большого количества разнообразной, неодинаковой по объему информации и решении задач различного плана на единицу времени" (О. М а к а р о в с к а, Кциповость мышления и формирование межкультурной компетенции, "Studia Rossica Posnaniensia" 2010, nr XXXV, с. 133-143). Б) Клиповое мышление рассматриваем как явление, т.е совокупность качественных характеристик в их наглядном воплощении, т.к. его можно рассматривать и как процесс, точнее, работу, действие соответствующих когнитивных механизмов. В) Эмотивный - определение дискуссионное, дефиницируемое учеными в зависимости от принадлежности к научной дисциплине. Здесь эмотивный - связанный с эмоциями, чувствами, душевным состоянием, переживаниями.

4 Об особенностях клипового мышления, обнаруживающихся на когнитивном уровне, см.: О. М а к а р о в с к а, указ. соч., с. 136-139. 
Примечательно, что основная особенность клиповости мышления заключается в ослаблении логико-рационального и усилении эмоционально-чувственного начала при восприятии информации, принятии и реализации решений, при реагировании на получаемые сведения, на различные события, на происходящее с самим индивидом, (не)знакомыми и его близкими, на поведение и реакции других людей, а также на каждую ситуацию общения. Основные признаки клиповости, проявляющиеся на эмотивном уровне, это:

- ориентированность на позитив, сопровождающаяся стремлением к избеганию конфликтов, разочарований, негативных эмоций, чувств, неприятных переживаний;

- повышенная эмоциональность, возможность неожиданных „всплесков" эмоций, в т.ч. немотивированной агрессии;

- склонность к поверхностности чувствования, избегание сильных, глубоких чувств, эмоций, состояний и переживаний, особенно негативных;

- экстериоризированность чувств, эмоций, переживаний, внутренних состояний

- деятельностная отзывчивость (готовность помочь делом, что-то предпринять) в сочетании с ослабленностью желания вникнуть в происходящее с другими людьми, в т. ч. с близкими, и до конца пережить возникшую ситуацию, т.е. действование по принципу было и прошлоб;

- преференциальность картинности чувств и эмоций („как в кино") и их овеществление (напр., небольшие подарки по поводу и без, материальные (не)приятные сюрпризы) или поведенческая материализация (напр., удивляющие поступки, (не)красивые жесты по отношению к кому-либо);

- склонность к эмоционально-чувственной калейдоскопичностиㄱ.

5 Экстериоризированность испытываемых чувств, эмоций, переживаний, душевных состояний понимаем как: а) их идентификацию, описание, вербализацию (напр., свободный, внутренне-невозбранный рассказ о них кому-либо); б) их намеренную демонстрацию (особенно негативных эмоций, что обычно сопровождается ожиданием участия и сочувствия со стороны окружающих), переживание на виду у окружения в сочетании с довольно слабыми и не всегда убедительными попытками их скрыть/умерить или с полным отсутствием таковых.

6 Примером сказанного является, допустим, ситуация, когда индивид в чем-то кому-то помогает, не задумываясь при этом о дальнейшей судьбе этого человека вообще и не интересуясь результатами помощи в частности.

7 Эмоционально-чувственная калейдоскопичность, по-нашему, заключается в жажде новых и все более острых эмоций и ощущений, в ожидании фейерверка эмоций, удовольствий и их постоянного обновления, в готовности к быстрой смене, к „перезагрузке” эмоций и даже чувств, как в компьютерных играх, где в любое время можно начать все заново. 
Эти общие признаки клиповости (во многом парадоксальные) обусловливают формирование ряда частных черт, ярко проступающих, скажем, у обучаемых РКИ. К ним относятся: позитивная настроенность и открытость на контакты с иностранцами; ожидание чего-то интересного от процесса межкультурного общения и от занятий по РКИв; быстрое падение интереса к монотонным межкультурным встречам и однообразно протекающему процессу обучения РКИ; интерес ко всему неизведанному, таинственному, чудесному; получение удовольствия от похвал и комплиментов; тяга к играм и развлечениям в ходе межкультурного общения свободного характера и на занятиях по РКИ; повышенная внушаемость (частотная и количественная)9'; ситуативная (чуть ли не обязательная, порой переходящая в рутинную) сопереживательность, заключающаяся в демонстрации здесь и сейчас сопереживания, нередко прикрывающего равнодушие; трудности при попытках справиться с негативными переживаниями и переключить свое внимание с них на что-то другое; достаточно точная идентификация своих чувств и эмоций.

Более того, в результате формирования клипового мышления для индивида особенно важным становится именно эмотивное $Я$ в сочетании с дистанцированием от любого негатива, со стремлением к положительным душевным состояниям и к движению-обновлению позитивных переживаний, осуществляемых в условиях внешней эмоционально благоприятной атмосферы, способствующей поддержанию внутреннего комфорта. В связи с этим в процессе осознания индивидом себя в мало- или непривычной ситуации межкультурного общения и адаптации к ней очень важными являются стабилизация эмоций, сдерживание возбуждения и переживания культурного шока как реакции на столкновение с иной культурой, нивелирование психического дискомфорта. Поэтому успешность межкультурной коммуникации (МКК), среди прочего, во многом зависит от того, насколько комфортным в эмоциональном плане является контакт с инокультурным собеседником.

8 А) Это подтверждают также исследования польских ученых (J. M a r t i n, Proces uczenia się stuchaczy w szkole językowej, [в:] H. K o m o r o w s k a, (red.), Nauka języka obcego w perspektywie ucznia, Warszawa 2011, с. 177-191). Б) Интерес тесно связан с эмоциями, чувствами, внутренними состояниями, что особенно подчеркивают психологи (см., напр.: С.Л. Р у б и н ш т е й н, Основы общей психологии, МоскваСанкт-Петербург-Нижний Новгород-Воронеж-Ростов-на-Дону-Екатеринбург-Самара-Новосибирск-Киев-Харьков-Минск 2009, с. 525-531).

9 Имеем в виду факт, что индивид способен легко, чуть ли не раздумывая, поверить в то, что ему часто повторяет один или несколько человек (частотная внушаемость), или в то, чего придерживаются, что осуществляют многие люди (количественная внушаемость). Названия частотная и количественная внушаемость даны нами условно. 
Центрированность на эмотивном $Я$, конечно, определенным образом сказывается и на протекании диалогического общения в заданной ситуации в процессе обучения РКИ. По нашим наблюдениям, учащимся труднее выступить в чужой статусной, должностной или профессиональной роли (напр., в роли кинозвезды, директора, полицейского) и легко - в роли себя самого или в социальной роли кого-то, но в эмотивной маске (напр., в роли обиженного покупателя, пациента-оптимиста, расстроенного чем-то кассира и т.д.). Возможно, поэтому обучаемые не очень охотно участвуют в ролевых играх, хотя у них обычно не возникает проблем с разыгрыванием типизированных ситуаций ${ }^{10}$ и с участием в ситуациях, разворачивающихся по четко разработанной схеме с опорой на интенции и эмоциональные реакции общающихся. Кроме того, учащиеся предпочитают реальные (повседневные, хорошо знакомые) и юмористические ситуации фантастическим („Вы находитесь в XXX веке..."), сказочным („Вы поймали золотую рыбку...”) или воображаемым („Представьте себе, что...”), тематические беседы - дискуссиям, высказывание своего мнения - его аргументации и обоснованию.

Безусловно, все перечисленные особенности, как это ни трюизматично, следует учитывать при реализации принципа ситуативности в процессе обучения РКИ польских учащихся вообще и при моделировании различных ситуаций общения в частности.

В силу же вышеизложенного логичным также представляется пересмотр трактовки самого принципа ситуативности. Дело в том, что при его толковании специалисты, занимающиеся вопросами иноязычного образования, обычно отталкиваются от определения понятия ситуациия, занимая одну из противоположных позиций, т.е. трактуя ситуацию или как совокупность внешних условий осуществления МКК, или как определенные взаимоотношения участников общения. Тогда в первом случае под принципом ситуативности понимается введение языкового материала „в виде диалогов, отражающих ситуации реального общения"11, во втором - „соотнесенность фраз с теми взаимоотношениями, в которых находятся собеседники"12.

10 Типизированные ситуации - регулярно повторяющиеся или достаточно часто воспроизводимые ситуации, к которым относятся, прежде всего, повседневные, привычные ситуации (дома, в городском транспорте, в магазине, кино, школе и т.п.), где иерархия, роли и поведение участников заранее предопределены. Формулировка дана с опорой на: Э.Г. А $з$ и м о в, А.Н. Щ у к и н, Словарь методических терминов, Санкт-Петербург 1999, с. 322, 339-340.

11 С.И. Л е б е д и н с к и й, Л.Ф. Г е р б и к, Методика преподавания русского языка как иностранного, Минск 2011, с. 37, [электронный ресурс:] http://www.philology.bsu. by/documents/Кафедра\%20прыкладной\%20лінгвістыкі/ Вучэбныя \%20дапаможнікі/ Методика\%20преподавания \%20РКИ\%20_учебное\%20пособие_.pdf (29.07.2012).

12 Е.И. П а с с о в, Н.Е. К у з о в л е в а, Основы коммуникативной теории и технологии иноязычного образования, Москва 2012, с. 189. 
Ввиду значительного влияния клипового мышления на эмотивную сферу индивида более обоснованной кажется точка зрения исследователей, выделяющих в ситуации непосредственного общения три составляющие: 1) внешние условия и факторы осуществления межкультурного общения (обстоятельства, события, объекты, место и время, окружение, внешние стимулы); 2) субъективно-личностные условия и факторы (внутренние стимулы, скажем, намерения, мотивация, потребности, цели, а также (взаимо)отношения общающихся, их характеристики, настроение, состояние и др.); 3) эмоциональную атмосферу, наличествующую здесь и сейчас ${ }^{13}$.

Отсюда ситуативность как принщип в широком смысле означает целенаправленное смысловое взаимодействие участников межличностной, лично-групповой, внутригрупповой коммуникации в рамках заданной ситуации, осуществляемое с учетом ряда внешних и внутренних факторов в условиях аудиторного обучения иностранному языку. В узком смысле ситуативность можно рассматривать в соответствующем аспекте, (не) выделяя конкретные факторы, напр., в нашем случае - в аспекте клиповости, с учетом эмотивного фактора ${ }^{14}$.

При моделировании ситуации общения для упражнений, не предполагающих заданности речевых реакций обучаемых, можно сосредото-

13 A) Составляющие даны по: A.S. R e b e r, E.S. R e b e r, Stownik psychologii, Warszawa 2008, с. 764. Б) Эмоциональная атмосфера - понятие дискуссионное, определяемое учеными в зависимости от репрезентируемой научной дисциплины, не имеющее общепринятой дефиниции. Эмоциональную атмосферу, вслед за Ж. де Риверой (на эту тему см.: М.Ю. У р н о в, Эмоциональная атмосфера общества как объект политологического исследования: постановка проблемы, Москва 2007, с. 18-27, [электронный ресурс:] http://www.civisbook.ru/files/File/Urnov.pdf (29.07.2012)), рассматриваем в узком смысле, т.е. как коллективное настроение, которое может быть задано новому участнику МКК, если она проходит на линии индивид - группа (или лично-групповой коммуникации) и индивид - индивид (в присутствии третьих лиц). Эмоциональная атмосфера может сформироваться уже в докоммуникативный момент (напр., в языковой группе перед началом занятий, в очереди на прием к врачу/чиновнику, между подружками), поэтому новый участник „погружается” в нее и не всегда способен ее разрядить.

14 А) Эмотивный фактор подразумевает, во-первых, взаимоотношения между участниками коммуникации и наличествующую эмоциональную атмосферу в аудитории, во-вторых, их эмотивное Я, т.е. психические особенности, среди прочего, обусловленные клиповостью мышления, а также, насколько это возможно, внутреннее состояние, в т.ч. здесь и сейчас. Б) Значимость эмотивного фактора как в процессе MKК, так и в процессе изучения иностранного языка неоспорима, поскольку позитивные и негативные чувства, эмоции, как известно, (не) способствуют возникновению, сохранению, повышению интереса к предмету обучения, а тем самым - поддержанию и росту мотивации к обучению в целом. 
читься на одном или всех ее главных элементах 15 , к которым относятся внешние условия (преимущественно место, обстановка, обстоятельства, эвентуально - время), Я-субъект, выступающий в определенной роли, эмоциональная атмосфера, (взаимо)отношения собеседников, коммуникативная задача. Остановимся на них несколько подробнее.

1. Внешние условия общения. Поскольку принцип ситуативности призван, прежде всего, способствовать подготовке учащихся к межкультурному общению на иностранном языке с его носителями, предпочтительной, по-нашему, является ориентация на реальные, а не малоили неправдоподобные условия протекания МКК.

Согласно Ф. Биллоузу, реальные ситуации охватывают: 1) то, что учащийся наблюдает здесь и сейчас (напр., в аудитории); 2) то, что ему хорошо известно из опыта повседневной жизни (то, что он уже видел и слышал); 3) то, с чем может столкнуться в будущем, но в настоящем ознакомиться только с помощью наглядных средств; 4) то, о чем узнаёт из письменно- и устноречевых сообщений 16 .

Конечно, ситуации первых двух типов не требуют дополнительных объяснений. При моделировании же ситуаций третьего типа (ситуации четвертого типа можно, скорее, вообразить, чем представить с помощью иллюстраций) необходимым становится использование визуальных и визуально-аудиальных средств наглядности, представляющих российские реалии, мало- или неизвестные польским обучаемым. Это особенно важно в контексте клипового мышления, обусловливающего устремленность учащихся к визуальности в самом широком смысле, т.к. обучающиеся (не)осознанно действуют согласно правилу лучше один раз увидеть, чем сто раз услышать. Поэтому визуальное предъявление условий осуществления коммуникации (напр., фотографии, видеоролики, рисунки, фрагменты документальных, художественных, учебных кинофильмов и даже мультфильмов) содействует более свободному „вхождению” учащегося в ситуацию общения и побуждает к активному участию в ней.

При словесном описании ситуации общения (после ее визуального предъявления, скажем, после просмотра соответствующих фотографий, размещенных в Интернете) следует выделить эмотивный компонент, напр.: „Вы зашли в московский магазин Пятерочка. Вы п р и я т н о у д и в л е ны, что он похож на Бедронку, и п о у в с т в о в а л и с е б я

15 Например, Е.И. Пассов и Н.Е. Кузовлева в процессе реализации принципа ситуативности во главу угла ставят лишь разные виды взаимоотношений между собеседниками (подробнее см.: Е.И. П а с с о в, Н.Е. К у з о в л е в а, указ. соч., c. 189-199).

16 F.L. B i 11 o w s, Technika nauczania języków obcych, Warszawa 1968, c. 17-20. 
в м а г а з и н е к а к д о м а. Однако вы никак не можете найти мятные пряники...".

Как показывает практика, невероятные, фантастические, сказочные ситуации лучше всего представлять изредка, причем в юмористическом ключе и с укрупнением эмотивного Я. Имеем в виду, что вместо формулировки „Вы на необитаемом острове...” предпочтительнее „К своему ужасу вы оказались ночью на необитаемом острове со Словарем русского языка С.И. Ожегова и дуршлагом...".

2. Я-субъект, выступающий в определенной роли. Несмотря на то что целесообразным представляется отказ от навязывания учащимся ролей, в которых они никогда не выступали, далеко не всегда в разыгрываемых диалогах оба партнера могут выступить в роли себя самого. Из этого вытекает: 1) оправданность сосредоточенности только на хорошо известных из личной практики учащимся социальных (пациент, пассажир, клиент) и коммуникативных (инициатор общения - отвечающий) ролях; 2) обязательность смены ролей в одной и той же разыгрываемой ситуации общения; 3) необходимость тщательной подготовки обучаемого к роли персонажа, в которого он должен воплотиться. Дело в том, что учащиеся не знают, как ведет себя, как реагирует, что говорит российский врач, продавец, полицейский, кондуктор, поэтому важность использования видеоматериалов и заранее подготовленных реплик неоспорима.

Как упоминалось, учащимся гораздо проще разыграть любую роль с наложением на нее эмотивной маски (напр., роль водителя такси в хорошем настроении, себя самого, возмущенного поведением знакомого и т.п.).

Отметим, что малообоснованным является одностороннее описание ролей и учет только мужских/женских ролей, напр., „Вам надо попасть в театр им. Вахтангова в Москве. Вы стоите в растерянности на улице Арбат, т. к. не знаете, в какую сторону вам идти. Вы решили это выяснить у у л и ч н о г о х у д о ж н и к а". Более корректной кажется формулировка: „Вы решили это выяснить у измученного жарой молодого уличного художника, мечтающего о глотке холодной газировки (у измученной жарой молодой художницы, мечтающей о глотке холодной газировки)".

3. Эмоциональная атмосфера. В определенных условиях эмоциональная атмосфера может быть задана: настроением одного из коммуникантов (напр., кассира в обменном пункте или самого Я-субъекта) при нейтральном настроении другого; консонирующим или диссонирующим настроением обоих коммуникантов; настроением группы лиц (напр., пациентов в очереди), навязанным новому участнику общения. 
Полагаем, что полезно моделировать ситуации не только с благоприятной, но и с неблагоприятствующей гармонизированному контакту эмоциональной атмосферой, хотя излишнее увлечение конфликтным речевым поведением и разрешением конфликтов обычно вызывает внутреннее сопротивление учащихся. При выстраивании же конфликтных ситуаций лучше использовать жесткую схему, предопределяющую (не)вербальные реакции общающихся, а также четко продумать завершение разговора. Практика показывает, что без этого возрастает вероятность неудачи в выполнении упражнения, т.е. диалог может переродиться в ссору (пусть и не всерьез) или не получиться вообще.

Эмоциональную атмосферу можно описывать с опорой на невербальное выражение эмоций, напр.: „Вы приехали в Калининград и хотите разменять деньги, но не знаете, где находится пункт обмена валюты, а на привокзальной площади как назло ни души. К счастью, вы замечаете стоящую спиной к вам женщину, радостно к ней направляетесь. Она внезапно оборачивается и п о д б о ч е н и в ш и с ь с в и ре по смотрит на вас...".

4. (Взаимо)отношения собеседников. Ввиду того, что этот аспект подробно разработан ${ }^{17}$, ограничимся одним замечанием. Важно, чтобы при моделировании ситуации общения однозначно охарактеризовать или отношение к собеседнику со стороны каждого из участников, или их взаимоотношения (напр., дружеские, прохладные, нейтральные). Дело в том, что учащимся сложно, если не невозможно, имитировать амбивалентность чувств (напр., симпатию и антипатию одновременно) или диссонанс между скрываемыми чувствами, эмоциями и поддерживаемым тоном общения (напр., неприязнь к партнеру или рассерженность на него в рамках ровного общения). Более того, обучаемые ясно осознают отличия занятий по РКИ от психологического тренинга, поэтому крен в данную сторону (особенно навязывание им ситуации со сменой чувств к собеседнику) воспринимается ими очень критично.

При определении (взаимо)отношений достаточно ограничиться их точным называнием, напр.: „Вы едете на поезде из Варшавы в Минск. Вашей спутницей является стеснительная девушка, ваша ровесница, скорее всего русская. Она вам с и м п а т и ч на, вы решаете с ней познакомиться...".

5. Коммуникативная задача. При постановке коммуникативной задачи, независимо от ее (не)проблемности и эмотивной „нагруженности", не следует забывать о том, что степень ее абстрактности - конкретности обратно пропорциональна степени эффективности выпол-

17 Подробнее см.: Е.И. П а с с о в, Н.Е. К у з о в л е в а, указ. соч., с. 189-203. 
нения ситуативных упражнений: чем выше ее абстрактность, тем ниже эффективность. А все потому, что учащиеся с клиповым мышлением, как это ни парадоксально, наряду с ясностью, упорядоченностью, логичностью представления, объяснения, формулировки заданий, целей, задач, учебного материала, организации и проведения занятий ценят „конкретику" в самом широком смысле, например, стремятся к достижению осязаемых, конкретных и пригодных в практическом плане результатов ${ }^{18}$. В связи с чем коммуникативные задачи в духе „Уговори своего друга заняться банджи-джампингом" воспринимаются обучающимися довольно скептически, впрочем, как и проблемные задачи типа „К чему приведет наложение запрета на использование ботокса?”, „Обсудите плюсы и минусы ухода мужчин в декретный отпуск”.

Проблематизирование в эмотивном ключе может касаться не только рассуждений, оценки и представления собственного мнения на тему характера, темперамента и правильности реакции собеседника/знакомого на какие-то обстоятельства, события, происшествия. Оно может затрагивать вопросы эмоционального и деятельного участия (напр., что делать в ситуации, когда сосед/-ка по общежитию все время расстроен/-а; как себя вести, когда сказанное вызывает у собеседника бурные, непредвиденные реакции; как среагировать на сообщение о трагическом событии, услышанное из уст первых/третьих лиц, или на рассказ случайного собеседника на вокзале, поведавшего о своих радостях(горестях), а также касаться сравнения родных культурных реалий с культурными реалиями ${ }^{19}$ страны изучаемого языка, удивившими, впечатлившими или не понравившимися учащемуся (даже если он ознакомился с ними опосредованно, например, с помощью учебного фильма).

Как показывает практика, одной из интересных коммуникативных задач является объяснение чего-либо, используя разные эмоции/чувства (напр., ласково, серьезно, шутливо, нетерпеливо, назидательно, с досадой) при обращении к одному и тому же или к разным собеседникам (напр., к сынишке русской подруги, российскому пожилому туристу/студенту/таможеннику).

При формулировке коммуникативных задач категоричные формы типа убедите, уговорите, объясните желательно смягчить, используя,

18 Это подтверждают также исследования польских ученых (J. M a r t i n, указ. соч., с. 185-187).

19 Под культурными реалиями подразумеваем все проявления культуры, трактуемой вслед за А.С. Карминым как „мир смыслов, которые человек вкладывает в свои творения и действия" (А.С. К а р м и н, Культурология, Санкт-Петербург 2001, с. 16), т.е. все, что проявляется в материальной, духовной, художественной и поведенческой форме. 
например, формы попытайтесь уговорить, убедить, объяснить, т.к. в реальной ситуации собеседника далеко не всегда можно склонить к чему-то, а некоторые вещи достаточно трудно растолковать (напр., доходчиво объяснить русскоязычному собеседнику значения и/или контексты употребления польского слова masakra).

При моделировании ситуаций общения для упражнений, предполагающих заданность речевых реакций обучаемых, весьма эффективным является разыгрывание диалога согласно эмотивно-интенциональной схеме ${ }^{20}$, в которой точно указываются интенции и эмоциональные реакции общающихся. К примеру, ситуация „Вы сильно обижены на своего/-ю сокурсника/-цу. Он/-а обещал/-а подбросить вас на своей машине в университет, но не заехал/-а за вами, из-за чего вы пропустили контрольную работу. Более того, он/-а не отвечал/-а на ваши звонки и сам/-а не позвонила. На следующий день вы встречаете его/ее перед занятиями" может разыгрываться с опорой на такую схему:

\begin{tabular}{|l|c|}
\hline $\begin{array}{l}\text { 1. Сокурсник/-ияа: радостное привет- } \\
\text { ствие. }\end{array}$ & $\begin{array}{c}\text { 2. Bb: ответ на приветствие обижен- } \\
\text { ным тоном. }\end{array}$ \\
\hline $\begin{array}{l}\text { 3. С.: вопрос о причине плохого настро- } \\
\text { ения. }\end{array}$ & $\begin{array}{l}\text { 4. Bbl: вопрос на тему причины сло- } \\
\text { жившейся вчерашней ситуации. }\end{array}$ \\
\hline $\begin{array}{l}\text { 5. С.: выражение удивления и непони- } \\
\text { мания, о чем идет речь. }\end{array}$ & $\begin{array}{l}\text { 6. Bb: объяснение раздраженным то- } \\
\text { ном, о чем был уговор и что случи- } \\
\text { лось. }\end{array}$ \\
\hline $\begin{array}{l}\text { 7. С.: внезапное озарение и понимание, } \\
\text { что забыл/-а об обещании заехать за } \\
\text { вами (все это упавшим тоном). }\end{array}$ & $\begin{array}{l}\text { 8. Вы: невербальная реакция, призван- } \\
\text { ная пристыдить провинившегося/ } \\
\text {-шуюся. }\end{array}$ \\
\hline $\begin{array}{l}\text { 9. С.: извинение сильно расстроенным } \\
\text { тоном. }\end{array}$ & $\begin{array}{l}\text { 10. Вы: принятие извинения все еще } \\
\text { обиженным тоном. Предложение } \\
\text { войти в аудиторию, чтобы не опоздать } \\
\text { на занятие. }\end{array}$ \\
\hline 11. С.: активное согласие. & 12. Вы: молчание с укором в глазах. \\
\hline
\end{tabular}

Во избежание монотонности, разыгрывание диалогов в заданных условиях общения с учетом эмотивного компонента, конечно, необходимо сочетать с другими заданиями, связанными с ситуацией общения, напр.:

- определение ситуации и чувств/эмоций героев во время просмотра фрагмента кинофильма без звука;

- придумывание/угадывание вариантов развития ситуации общения во время прослушивания записи диалога или после прочтения описания фрагмента заданной ситуации;

20 Название схемы дано нами условно. 
- идентификация шумов окружения или описание (придумывание) внешних условий ситуации общения при прослушивании записи диалога/полилога;

- описание чувств/эмоций ее участников по тону голоса в ходе прослушивания записи диалога или по выражению лица во время просмотра визуальных некинематографических материалов (фотографий, рисунков) и пр.

Конечно, реализации принципа ситуативности в процессе обучения польских учащихся межкультурному общению на русском языке с учетом клипового мышления (точнее, результата его воздействия на эмотивную сферу) требует от преподавателя вложения определенных усилий, систематичности, последовательности, креативности. Однако, выражаясь метафорически, игра стоит свеч, ибо все это позволит вовлечь учащихся в процесс активного овладения и эффективного усвоения изучаемого языка. 